\title{
La burocracia en el arte. El discurso judicial en la obra de E.A. Vigo
}

\author{
Ana Bugnone \\ Universidad Nacional de La Plata - CONICET
}

\begin{abstract}
Resumen
Este artículo se centra en el estudio de la obra del artista vanguardista argentino Edgardo Antonio Vigo, especialmente en la forma en que combinó arte y burocracia a través de la adopción y distorsión del lenguaje judicial. Se analizan algunas obras donde aparecen las formas lingüísticas, los géneros, la materialidad y la visualidad del discurso judicial, cuyo uso es irónico y crítico, desubicando el lenguaje judicial de su lugar original y natural. Vigo emplea la firma, los hilos y los términos específicos de dicho lenguaje como parte de una utilización excéntrica de las formas de un espacio al que pertenece por su trabajo diario, pero de modo impropio por no ser un sujeto autorizado en términos de los límites que ese discurso impone. Asimismo, se examinan los trabajos artísticos donde aparece una crítica al sistema judicial por injusto y desigual. Estos elementos llevan a verificar la politicidad de estos trabajos, en términos de una configuración interna de la obra que se vincula con un medio al que no pertenece, que hace público y al que permite circular por fuera de sus espacios normales y reglados.
\end{abstract}

\section{Palabras clave}

- arte · burocracia - Edgardo Antonio Vigo - discurso - lenguaje judicial · política

\begin{abstract}
This paper focuses on the study of the work of Argentinian avant-garde artist Edgardo Antonio Vigo, particularly on the way he combined art and bureaucracy through the use and manipulation of legal language. We will analyze some
\end{abstract}


works that feature the linguistic forms, genres, and the material and visual nature of legal discourse used in an ironic and critical way, which put legal language outside its natural, original place. Vigo employs the signatures, threads and specific terms of said language as an eccentric use of the forms of a space that he belongs to because of his everyday work, but still in an inappropriate way given the fact that he is not an authorized person in terms of the limits imposed by such discourse. Those artworks that criticize the judicial system for being unequal and unfair will also be analyzed. These elements prove that his works have a political character in terms of their internal configuration which is linked to an environment it does not belong to, which it makes public and which allows it to exist outside its usual, regulated spaces.

\section{Key words}

- Art · Bureaucracy · Edgardo Antonio Vigo · Discourse · Legal
Language · Politics

Una de las zonas más originales y significativas de la poética del artista vanguardista argentino Edgardo Antonio Vigo (1928-1997) es la que surge de la combinación que realizó entre arte y burocracia a través de la utilización del discurso judicial en la producción artística, cuyo origen está directamente vinculado con su trabajo como empleado de los Tribunales. Esta operación, como veremos, tiene implicancias políticas que van más allá del mundo artístico. Vigo utilizó aspectos del discurso judicial, como los sellos, las firmas y los textos jurídicos desde los primeros años de la década de los cincuenta. Este uso consistió, por un lado, en que incorporó elementos propios del lenguaje de las leyes, las disposiciones judiciales y burocráticas, utilizándolo tanto en su forma declarativa como probatoria, en la narración de los hechos y en la constatación de las acciones. Por otro lado, el artista usó uno de los rituales vinculados con la escribanía y elementos visuales de ese discurso, como los sellos personales y fechadores.

Vigo trabajaba como empleado de los Tribunales Civiles de La Plata, lo que no solo le dio un sostén económico, sino una materia que incorporaría en su poética para desnaturalizarla de su lugar original. En su juventud quiso dedicarse a la aviación, razón por la cual se presentó en la Aeronáutica de Córdoba, pero no logró ingresar. Luego comenzó a trabajar como practicante en los Tribunales y cuando se produjo una vacante en la Aeronáutica, decidió rechazar la oferta, ya que se sentía muy integrado al mundo judicial. El artista también comentó que se deslumbró con el lenguaje de ese mundo, con la oficina como espacio físico, y que 
esto representaba una novedad en su vida, ya que no tenía familiares vinculados con lo judicial (entrevistado por M. Curell, 1995). Este punto será crucial para entender la magnitud de la dislocación del lenguaje judicial en manos del artista.

En los Tribunales, Vigo cosía expedientes, una práctica que incorporó a su estrategia material de producción artística. El uso de los hilos, los ojalillos, las carpetas de cartulina y los sellos, objetos directamente vinculados con su tarea en Tribunales, formaron parte de su obra. Fue allí donde un compañero le regaló su primer libro de historia del arte y donde otros compañeros decidieron anotarlo en la Escuela de Bellas Artes en la carrera de Dibujo. Así, el comienzo de su relación formal con el arte se vinculó estrechamente con el mundo de la justicia. Se vinculó con la Asociación Judicial Bonaerense y con la revista que esta editaba, En marcha, encargándose de la sección xilografía.

Vigo estimaba el valor de la libertad creativa y sintió que en su trabajo de judicial también podía ejercerla, así dijo «Puedo ser libre en mi taller, en mi lugar de trabajo, en mi escritorio, puedo ser un burócrata y sin embargo ser libre» (entrevistado por M. Curell, 1995). Para comprender la complejidad de esta posición asumida por Vigo, es necesario señalar que llamó «revulsiva» a su propuesta artística, es decir que pretendía modificar la mirada o la subjetividad desde un posicionamiento "anti burgués», lo cual parece contraponerse con el grado de integración que tuvo Vigo a la institución judicial, a pesar del carácter mayormente aristocrático y garante del orden social. No obstante, el propio artista no consideró que hubiera contradicciones entre ambos mundos y su estrecha vinculación con lo judicial le dio un anclaje económico y social que, a juzgar por sus declaraciones, no generó incompatibilidades. Fue tal vez esa misma adaptación la que le permitió incorporar elementos y materialidades de lo judicial a su producción artística, que, con diversos matices, iban desde la ironía hasta la crítica política.

En los Tribunales, hizo de la oficina donde trabajaba - y de otros despachosun espacio de expresión: colgaba objetos y xilografías, los que convirtieron a ese lugar formal en una zona de arte de vanguardia. Esa oficina, que según su archivo, tenía la forma de un hexágono, fue tan significativa que dio el nombre a una de sus revistas, Hexágono '71. Así, la apropiación de distintos aspectos del discurso judicial puede entenderse en el marco de esa idea de libertad, y su trabajo en Tribunales, lejos de constreñirla y a pesar de las contradicciones, se presentó como una oportunidad para ampliarla.

Para comprender el significado de la operatoria que realizó Vigo respecto de los lenguajes del mundo judicial, es necesario mencionar que el lenguaje utilizado en el mundo judicial es llamado «técnico», «especial» o "tecnolecto» es decir, propio de cada ámbito que, tomando como base el lenguaje natural, posee formas y significados particulares. En el caso judicial, se trata de un lenguaje especialmente intrincado, con una sintaxis artificiosa y muchas veces poco clara, lo que ha fortalecido su carácter de exclusividad en el ámbito judicial y una dificultad generalizada en la comunicación con el público en general. Lo que interesa de este tipo de lenguaje para interpretar la obra de Vigo es que además de utilizar uno específico, ajeno al mundo del arte, el judicial también puede entenderse como un discurso, especialmente centrado en el orden y el control social. Según Michel Foucault, no se trata solo de un tipo de lenguaje especial entre otros, sino uno fundamentalmente utilizado como modo de control sobre las sociedades a través del tiempo. Esto se debe a que «en toda sociedad la producción del discurso está a 
la vez controlada, seleccionada y redistribuida por cierto número de procedimientos que tienen por función conjurar sus poderes y peligros, dominar el acontecimiento aleatorio y esquivar su pesada y temible materialidad" (Foucault, 2012:14). En el mismo sentido, Jacques Rancière (2007) sostiene que el uso de la lengua está sometido a un orden que organiza, jerarquiza y autoriza quiénes pueden usarla y disponer de ella y quiénes no y que algunos usos fuera de esa organización son políticos porque ponen en cuestión la partición de lo sensible.

Uno de los discursos que mejor expresa estos los procesos de exclusión de los que habla Foucault (2012) es el judicial, porque su constitución como discurso del control exagera las limitaciones a través de las ritualizaciones, la selección de productores autorizados y el uso de terminología específica. Esto denota que en el discurso se ponen en juego cuestiones de poder. Una de la de las formas en que Vigo desvirtuó esos límites del discurso es a través de la ironización, dado que al producir sentencias para las que utilizaba géneros, formas y materialidades del mundo jurídico y administrativo, estaba burlándose de esas formalidades y rituales, y demostrando su contrario, la irracionalidad de su uso fuera del espacio «natural» de su utilización. En la medida en que el discurso judicial debe atenerse a estas restricciones, su uso fuera de estos parámetros, descolocado de los sujetos, circunstancias, rituales y objetos pertinentes, hace de él un discurso mal-dicho, que, en lugar de repetirse y fijarse, se desgrana en el ámbito de una experiencia que lo separa de la normalidad.

La utilización que realizó Vigo del discurso judicial puede dividirse en dos grandes grupos: el primero, trabajos en los que prevalece la forma de dicho discurso; el segundo, los que hacen hincapié en el contenido, acercándose a una crítica al sistema judicial en sus aspectos más injustos. En relación con esta zona de su obra, cabe mencionar que las acciones artísticas, participativas o performáticas que realizaba Vigo tenían una particularidad: registraba por escrito o fotográficamente (o ambas cosas) cada paso que realizaba. Algunas veces, incorporaba esos registros en distintas obras vinculadas entre sí y, además, formaba con esa documentación carpetas que archivaba cuidadosamente. Al mismo tiempo que protegía la memoria de las mismas, Vigo le dio un carácter particular a ese registro, utilizando frases, palabras, sellos y procedimientos propios del ámbito judicial.

\section{La distorsión del lenguaje}

Vigo realizó entre 1970 y 1972 el Señalamiento VIII, que consistió en retirar un poco de agua del Río de la Plata, al año siguiente, devolverla al río y tomar cuatro muestras de una nueva toma. Según la descripción que realizó el artista, en la primera oportunidad había sumergido trescientas tarjetas en el agua, «a las que previamente había impreso un texto donde se certificaba que las mismas habían estado sumergidas durante un tiempo-horario determinado" (Archivo personal de E. A. Vigo). El artista escribió el documento $« \mathrm{H}_{2} \mathrm{O}-$ Relato de la acción» que forma parte del señalamiento, y su título da señales de que recogió la frase que usualmente encabeza en el derecho la descripción de una acción en un escrito legal. Allí, narra y 
certifica la acción artística, utilizando un lenguaje que obedece al discurso judicial: "prosiguiendo con los actos», "procedí», "conjuntamente se acompaña», así como describe las tareas realizadas, con una especificación de las características y una organización temporal cronológica que adecúan el texto al género de ese tipo de relatos en los escritos judiciales. Finalmente, utiliza un certificado oficial del Ministerio de Obras y Servicios Públicos, fechado, firmado y sellado, además de la impresión de un sello fechador. El nivel de detalle y exactitud que aparece en este documento, como en tantos otros del artista, excede la simple necesidad de registrar un episodio artístico efímero: Vigo decide dar la forma de documento judicial.

Esta explicación se publicó en la revista belga Amenophis, en la que se agregó una tarjeta con un espacio especialmente reservado para que el receptor se la enviara a Vigo y él lo mojaría con el agua del señalamiento como prueba de la acción realizada. Luego, la volvería a enviar al receptor de la revista. De este modo, en la tarjeta Vigo certifica la veracidad del acto realizado y al mismo tiempo se compromete a realizar otra acción: al mojar la tarjeta se constituye una "prueba» y se expresa, además, la intención de hacer participar al público. Este trámite de tinte burocrático, con regulaciones precisas - tal como suele hacerlo el mundo estatal y especialmente judicial - invita al lector a intervenir en el proceso de la acción, apuntando a uno de los leit motiv de la poética de Vigo: la participación del público. Asimismo, la publicación de este documento en una revista apela a la difusión de la acción que, sumada a la invitación a intervenir, implica un ofrecimiento de ese discurso judicial por fuera de los límites de su ámbito natural. Además, ese llamamiento a que cualquiera pueda ser parte de la constitución de una prueba también cuestiona las inclusiones, exclusiones y designación precisa de sujetos autorizados dentro del sistema judicial. Por otro lado, hacer constar este tipo de situaciones parece mostrar el sinsentido de algunas acciones judiciales y de la burocracia en general si se las considera de modo aislado — como lo hace Vigo— y no como elementos del ritual judicial y de los procedimientos que le otorgan legitimidad.

Estos y otros textos de Vigo finalizan con «conste» y su propia firma, colocando, así, una palabra resonante en los expedientes judiciales y un elemento fundamental como la signatura, que da cuenta de la autoría y lo responsabiliza de lo contenido en el documento. Si en el discurso judicial lo central del certificado es que esté firmado por una persona competente, la firma de Vigo o de un crítico de arte o del receptor, se posiciona como elemento impropio e irónico que desajusta tanto el uso normalizado de este tipo de documentos, así como la recepción de un objeto que se presenta como obra y que, por lo tanto, no se espera de él ninguna consecuencia legal. Frecuentemente se ve que las obras de Vigo, específicamente aquellas que van acompañadas o están constituidas por textos escritos, están rematadas por su sello personal y la firma. Esta forma particular de finalizar un texto, además de vincularse con el mundo judicial y administrativo y, refiere al modo especial en que Vigo se relacionó con su firma como autor. Siguiendo a Derrida, la firma "pretende ser la presencia del "autor" como "persona que enuncia" como "fuente", en la producción del enunciado (...) [e] implica la no-presencia actual o empírica del signatario (...), señala también y recuerda su haber estado presente en un ahora pasado, que será todavía un ahora futuro» (1998: 370). Esta 
omnipresencia autoral a través de la firma tensiona la pretensión de Vigo de ser un autor anónimo o solo proyectista ya que, por el contrario, se apropia de este aspecto de los escritos judiciales, afirma su existencia en tanto individuo y genera una identificación única y singular entre la firma y lo que se firma.

Asociadas a la revista que inició en el ańo 1971, Vigo produjo «ediciones» con el sello editorial «La Flaca grabada. Hexágono '71». Una de ellas es el Informe O’OOA de la acción titulada 200 llaves que viajaron de La Plata/Buenos Aires/La Plata, del que realizó una tirada de doscientos ejemplares. Vigo reunió doscientas llaves abrelatas y las transportó desde La Plata hacia Buenos Aires. Las llevó hasta al Instituto Di Tella, donde el crítico de arte Samuel Paz certificó la llegada de las llaves y luego Vigo regresó a La Plata con ellas. En el trayecto de ida y vuelta, así como en el encuentro con Samuel Paz, Vigo tomó nota de los datos y horas exactas en que ocurrieron los hechos, así como fotografías que los «documentaron». Con todo ello Vigo armó el Informe donde, además de la información y las imágenes, se encuentra una hoja de la que cuelga la llave abrelatas atada a un hilo. Además de aspectos del discurso judicial, se advierte en esta obra la presencia de un tercer involucrado, un participante calificado que certifica la acción del viaje. La pertenencia a una institución de relevancia en el arte (visible por el uso del sello) da mayor formalidad y credibilidad al uso del certificado, al mismo tiempo que religan la obra y su certificación al mundo del arte y a la renombrada institución. Por otro lado, la numeración no correlativa de los pasos que implicó la acción (1, 3, 2, 4) —aunque los horarios en que ocurrieron sí están ordenados- y el uso de los paréntesis en forma invertida, por ejemplo en «)aprox.(", mantienen restos de la poesía visual, en las que utilizaba letras y números dándoles un lugar visual, apartados de su función normal, al tiempo que los incorpora a un informe cuyo formato es eminentemente burocrático.

En estos y otros trabajos similares, el uso del discurso judicial se convierte en un elemento ineludible, pasando a ser el aspecto central, tanto porque los textos implican una referencia a un hecho que ya no es visible por haber sido efímero, como porque, en otros casos, es el elemento constitutivo de la propia obra. En las manifestaciones efímeras, Vigo parece apelar a la idea que representa la frase latina de uso corriente en los expedientes judiciales, y que forma parte de la lógica material de su funcionamiento: Quod non est in actis, non est in hoc mundo ("Lo que no consta en actas, no existe en este mundo") refiriendo a que todo lo alegado y probado, debe constar en el expediente, de otro modo, no existe. En estos trabajos de Vigo hay una trasposición de esta máxima de los expedientes a las obras y acciones, y con esto se vale, nuevamente, de un elemento externo y específico de otro ámbito. Esto sucede, además, en una poética, como la de Vigo, que presenta entre sus particularidades la proposición de utilizar materiales «innobles» y la realización de "presentaciones» en lugar de exposiciones, en consonancia con su posición vanguardista. Estas elecciones implicadas en la obra efímera, entran en tensión con la opción de probar, como en un caso judicial, la existencia de esos mismos hechos que se proponen distantes de las obras de arte tradicionales. $\mathrm{O}$ bien, es por ese carácter vanguardista que se hace necesario, para Vigo, constatar al menos probatoriamente, su existencia. La presencia de la prueba o el certificado devuelven simbólicamente la idea de que la obra tomó cuerpo, como una resistencia a la pérdida total de su entidad que formaba parte del arco de propuestas de los artistas vanguardistas de la época. 
En el Señalamiento IX, Vigo enterró un taco de madera en el patio de su casa y al año siguiente lo desenterró. Así, el Enterramiento y desenterramiento de un taco de madera de cedro también fue certificado, pero en este caso por la presencia de dos compañeros que llamó «testigos» (la escultora Graciela Gutiérrez Marx y el fotógrafo Juan José Estéves), y por una escribana que formalmente realizó un acta de constatación de lo ocurrido y la "protocolizó». Además, Vigo cortó setenta trozos del taco original con los que formó la edición Múltiples acumulados y sacó fotos que ofreció como "prueba» o «testimonio». Produjo, además, un texto que narra lo realizado en el señalamiento donde explica con tono administrativo el procedimiento seguido con el taco de madera y menciona la actuación de la escribana. En este caso, además de los indicadores de la apropiación del discurso judicial, se presenta la máxima configuración de la utilización de ese discurso en la acción artística: no solo la palabra y la imagen de ese lenguaje, sino el procedimiento y la acción concreta de un representante del estado, específicamente, un experto en procedimientos de dar fe que, según la doctrina del derecho, otorga validez y legalidad al acto, y plasma todo en un documento público. Sin embargo, el uso que dio Vigo a esta certificación no es el de la realización de algún trámite, sino el de demostrar que ese señalamiento que se encuentra entre los que él mismo clasificó como "privados», efectivamente ocurrió. Así, lo efímero de la acción que constituye su sustancia, queda atenuado por el registro fehaciente en un documento público. Esto permite no solo reforzar la acción frente a otros, sino brindar una objetivación más prolongada en el tiempo y mostrarla en diferentes ocasiones. La aplicación de un proceso de la escribanía a una acción artística aparece como una burla hacia los procedimientos jurídicos y una demostración de su ineficacia o insensatez. Asimismo, ironiza sobre la función del artista, que se ve necesitado de aquel trámite para constatar que ha realizado un señalamiento, el cual, a diferencia de las obras de arte tradicionales, no podría ser captado como hecho artístico fuera del momento de su realización.

Otros artistas en la misma época también utilizaban dispositivos textuales similares para la producción artística a través de la elaboración de declaraciones o información documental que se ofrecían a la audiencia en reemplazo del objeto artístico. Lo que caracteriza a Vigo es la sistematicidad y repetición con que utilizó los géneros, las fórmulas y la terminología del discurso judicial y la presencia misma de los objetos a los que hacía referencia, no siempre reemplazados por la palabra, aunque en estrecha vinculación con ella. Las apropiaciones dislocadas que ejerce Vigo del discurso judicial desenmarcan tanto el espacio propio de su uso como los autores e interlocutores posibles. En tanto el programa de Vigo implicó un cambio en la concepción de la obra, el autor, el público y los lugares y modos de "presentación", puede considerarse que en aquellas apropiaciones abre también una forma de obra artística que se desencaja de las expectativas culturales más instaladas. En este sentido, implica una intervención de un mundo ajeno en la práctica artística, donde aparecen la sorpresa y la ironía como formas de descontracturar el efecto de la obra. Al mismo tiempo, provoca una extensión desatinada, por impropia, de las formas judiciales hacia otros espacios. Así, mientras Vigo denostaba las prácticas burguesas en el arte, anexó o constituyó trabajos artísticos con materiales y operatorias que no solo pertenecen a ese sector, sino que permanecen más o menos inaccesibles e intocables para otros estratos sociales. 


\section{La crítica política}

Vigo también captó aspectos que constituyen el contenido del discurso jurídico y contradijo el «tabú del objeto» (Foucault, 2012) que limita los discursos: el artista tomó como tema de sus obras elementos que forman parte de lo que no puede ser dicho de cualquier modo o circunstancia, de lo que no puede ser hablado en formas ajenas a un estatuto adecuado. Esto implicó que Vigo no solo trabajara sobre un objeto intocable o exclusivo, sino también una acusación política que mostraba arbitrariedades y atropellos sobre los derechos de las personas. De este modo, al mismo tiempo que se apropió de las formas discursivas, abarcó también una crítica social y política sobre el funcionamiento de la estructura judicial.

En el número cd de Hexágono '71, de 1973, Vigo publicó una poesía visual que no solo toma un tema jurídico, sino que implica también un ataque al sistema judicial en general. Allí la palabra «inocente» pasa por un embudo del que sale la palabra «culpable». Debajo se encuentra la frase «La ley del embudo» y un sello de Vigo. Esta obra muestra la idea de que una persona inocente, al pasar por el sistema (capitalista, dominante, militar, judicial), se convierte en culpable. Vigo muestra que se ha invertido el principio de presunción de inocencia («Toda persona es considerada inocente hasta que sea declarada culpable»), y hace que el inocente que pasa por el «embudo», sea considerado culpable. «La Ley del embudo» es conocida popularmente como una metáfora de la desigualdad o la injusticia, razón por la cual interpretamos que Vigo asume una crítica hacia todo el sistema judicial. La ley del embudo, puede entenderse como uno de los casos en que Vigo toma una posición política, denuncialista y convergente con las ideas críticas de diversos sectores de la sociedad, especialmente de la nueva izquierda, sobre una realidad que considera injusta, responsabilizando al estado. Al mismo tiempo, compone la obra de un modo que conserva la raigambre de su propia poética al vincularse directamente con la poesía visual.

Emparentado con este trabajo, Variante jurídica, publicado en el cf de Hexágono '71 a finales de 1973 o principios de 1974, es otro de los que toman como tema algún aspecto del contenido del discurso judicial. Con el subtítulo «Relación: Estado / Individuo", la obra consta de dos columnas: en la izquierda dice "Ayer» y en la derecha, «Hoy». Debajo de la primera dice "Quita de libertad por hecho probado» y al lado, bajo la columna «Hoy», se lee "Quita de libertad por hecho supuesto». En la segunda fila, bajo la columna «Ayer» expresa «Demostración de culpabilidad por el Estado», en «Hoy» dice «Demostración de inocencia por el individuo». Este texto es una clara denuncia sobre las violaciones a los derechos de las personas por parte del estado en relación con las prácticas judiciales: la condena por un hecho probado y la presunción de inocencia. Vigo muestra que ambas garantías están siendo quebrantadas, en la medida en que el sistema político se orientaba cada vez más a la derecha, a pesar del breve lapso de gobierno peronista donde Héctor Cámpora recogió las demandas de los jóvenes militantes de la nueva izquierda.

Finalmente, Vigo utilizó una ley en su Tríptico remarcado (Ley 18188), editado por Diagonal Cero en 1970. Esta ley establecía el valor de la moneda local, los "pesos ley 18188», entre 1970 y 1983. Vigo utilizó el nombre de esa norma para realizar un tríptico perforado con números —una práctica utilizada también en 
otras obras - que en su interior contiene tres tarjetas colgadas de hilos. La primera, en forma triangular, dice "Biafra», haciendo referencia a uno de los países más pobres de África; la segunda, romboide, expresa «Viet-Nam», en clara alusión a la guerra allí desatada y que fuera rechazada por amplios sectores en distintos países; la tercera es un círculo - una forma cara a la poética de Vigo - con una suma algebraica: "Favelas + villas miserias = Latinoamérica», es decir, que relaciona los asentamiento pobres en Brasil y Argentina con la totalidad del subcontinente. Vigo expresa en Tríptico enmarcado (Ley 18188) la relación entre las políticas económicas de los países, a través de la referencia a esta ley, la miseria, el hambre y la guerra. Este trabajo se encuentra ligado a lo judicial el uso de una ley en su título, y por un aspecto de su materialidad, los hilos, ligado a la tarea de coser expedientes que Vigo realizaba a diario.

\section{Reflexiones finales}

En los casos que vimos, Vigo estructura sus obras a través de un discurso que pertenece al cuerpo judicial y en esa utilización lúdica, irónica o crítica, hace visible que ese lenguaje no pertenece al arte, ni siquiera a la lengua común. No se trata cualquier jerga de un ámbito particular, sino donde toma cuerpo una de las formas más concretas de afirmación de un orden social: la aplicación de la ley. Así, Vigo intercepta un aspecto del funcionamiento del sistema - o como dice Rancière, el orden, la policía - disociándolo de su lugar normal y, al ofrecerlo en una acción artística, permite una apropiación descentrada, fuera de sus límites naturales. Vigo conforma un dispositivo en el que incluye el texto, la imagen, las prácticas y los elementos de la materialidad de lo judicial.

Vigo hace de lo incomprensible - por específico, técnico y arcaico- algo que exhibe el valor de lo artístico, que se muestra y se ofrece para generar una experiencia estética. Desvirtúa su condición de lenguaje de especialidad solo accesible y comprensible para unos pocos y lo pone a circular, demuestra que hay una politicidad en sus obras, entendida como «una articulación interna a la obra que reflexiona críticamente sobre su entorno social desde su propia organización de significados y su propia retórica de los medios, desde sus propios montajes simbólicos», y donde no hay una correspondencia dada entre forma artística y contenido social (Richard, 2005:17). En esta zona de su poética hay un tipo de relación con lo político que desestabiliza aspectos del orden social a través de una desorganización de los discursos que implica también una distribución de los poderes. Vigo hace fallar los procedimientos de exclusión del discurso que limitan el uso por parte de sujetos o en circunstancias ajenas a las originalmente establecidas y que determinan que ciertos objetos del discurso no pueden ser empleados de cualquier modo. Además, el artista implica a otros en su uso. En este sentido, encuentra una grieta en el control del discurso, demostrando que es posible evadirlo y hacer ver o leer una voz no permitida. Esto último puede entenderse también con Rancière (2006), ya que las voces no autorizadas son aquellas que solo producen «ruido» — así también lo advierte Foucault—y por eso generan un disturbio, una 
desorganización en el orden de las jerarquías, posiciones y disposiciones del orden policial y sus reparticiones en lo social. En el caso de Vigo, su obra aparece en ese lugar descentrado que hace aparecer una voz en lugares y formas inapropiadas, particularmente movilizando un discurso caracterizado por su relación con la ley, el orden social y la sanción, y en ese sentido su procedimiento es político. Así, los juegos irónicos del lenguaje judicial de Vigo, los rituales jurídicos transformados en performances y su circulación extramuros de los circuitos normales, pueden pensarse como intentos de poner a la vista que hasta los espacios y prácticas más consolidados como excluyentes de los oídos y las voces de los no autorizados, son pasibles de ser alterados y descolocados como disidencia de la finitud técnica y específica: una politicidad que apunta directamente sobre una de las prácticas socioculturales de la dominación.

\section{Referencias bibliográficas}

Derrida, J. (1998). Márgenes de la filosofía. Madrid: Cátedra.

Foucault, M. (2012). El orden de discurso. Buenos Aires: Tusquets.

Rancière, J. (2007). El desacuerdo. Política y filosofía. Buenos Aires: Nueva Visión.

Richard, N. (2005). «Arte y política»; lo político en el arte. En Oyarzún, P., Richard, N. y Zaldívar, C. (Eds.). Arte y Politica (16-17). Santiago de Chile: Consejo Nacional de la Cultura y las Artes y Universidad Arcis.

\section{Bugnone, Ana}

